\title{
Dependence of Nanotextured Titanium Orthopedic Surfaces on Electrolyte Condition
}

\author{
Sachin M. Bhosle ${ }^{1,2}$, Radheshyam Tewari1 ${ }^{1}$ Craig R. Friedrich1 \\ ${ }^{1}$ Multi Scale Technologies Institute, Michigan Technological University, Houghton, USA \\ ${ }^{2}$ Vidya Pratishthan's Kamalnayan Bajaj Institute of Engineering and Technology, Baramati, India \\ Email: smbhosle@mtu.edu
}

How to cite this paper: Bhosle, S.M., Tewari, R. and Friedrich, C.R. (2016) Dependence of Nanotextured Titanium Orthopedic Surfaces on Electrolyte Condition. Journa of Surface Engineered Materials and Advanced Technology, 6, 164-175.

http://dx.doi.org/10.4236/jsemat.2016.64015

Received: July 16, 2016

Accepted: October 9, 2016

Published: October 12, 2016

Copyright $\odot 2016$ by authors and Scientific Research Publishing Inc. This work is licensed under the Creative Commons Attribution International License (CC BY 4.0).

http://creativecommons.org/licenses/by/4.0/

\begin{abstract}
Electrochemical etching of titanium alloy in a fluoride-containing electrolyte results in ordered nanotextured surfaces. The reproducibility of nanotextured surfaces depends on several process parameters, most notably the fluoride ion concentration in the electrolyte. In the present work, electrochemical etching of Ti6Al4V alloy foils in ethylene glycol containing $0.66 \mathrm{wt} \% \mathrm{NH}_{4} \mathrm{~F}$ and $2 \%$ deionized water was carried out at $60 \mathrm{~V}$ for 45 minutes. This paper describes the depletion of fluoride ion concentration and contamination of electrolyte upon reuse. Inductively coupled plasma-optical emission spectroscopy was used to measure the dissolution of metal oxides in the electrolyte during etching. We found increasing concentration of the alloy elements $\mathrm{Ti}, \mathrm{Al}, \mathrm{V}$ contaminated the electrolyte due to repeated reuse of the electrolyte. The results show an appreciable log-linear depletion of fluoride ion concentration resulting in a changed surface morphology, chemical composition and etched volume. This paper provides an important insight to changes in surface morphology and surface chemistry with extended reuse of the etching electrolyte, useful for regulatory approvals.
\end{abstract}

\section{Keywords}

Implants, Anodization, $\mathrm{TiO}_{2}$ Nanotubes, Fluoride Concentration, Titanium

\section{Introduction}

Titania nanotubes on orthopedic implants are of scientific interest due to their biocompatibility. Ordered nanotextured titanium surfaces have been an attractive approach as a material for applications in the biomedical field [1]. One of the challenges is to improve bone bonding because of the lack of porosity and in growth of apatite deposits in the pores at the bone-implant interface [2]. This results in loosening of the 
implant due to a lack of osseointegration, or osteolysis, which calls for modifications in implant surface. $\mathrm{TiO}_{2}$ nanotubes can increase bone-like apatite formation, cell proliferation and osseointegration [3]. $\mathrm{TiO}_{2}$ tubes can be fabricated on the surface of titanium implants using an electrochemical anodization technique. Ordered nanotubular titania structures can be fabricated in the presence of fluoride ions in an electrolyte using appropriate anodization parameters [4]. The controlled morphology and thickness of porous $\mathrm{TiO}_{2}$ nanotextured films can be achieved by controlling the anodization parameters [5]. Fabrication of $\mathrm{TiO}_{2}$ nanotubes during electrochemical anodization is a result of the formation of an anodic oxide layer followed by field-assisted chemical dissolution [6]. Fabricated nanotubes show compositional and morphological variations as a result of variations in process parameters, including anodization voltage, time, and fluoride concentration. The fluoride ion concentration in the electrolyte is one of the important parameters to achieve repeatability of the etched surface. Fluoride concentration in the electrolyte is reported to be the most influential factor for titania nanotubes etched in ethylene glycol- $\mathrm{H}_{2} \mathrm{O}$ electrolyte containing $\mathrm{NH}_{4} \mathrm{~F}$ [7]. The fluoride ions in the electrolyte are reported to perform two important functions after initial oxide growth on the Ti surface. First, it reacts with dissolved $\mathrm{Ti}^{4+}$ ions at the oxide-electrolyte interface and forms soluble $\left[\mathrm{TiF}_{6}\right]^{2-}$ complex. Secondly, it chemically dissolves $\mathrm{TiO}_{2}$ and then forms the $\left[\mathrm{TiF}_{6}\right]^{2-}$ complex [8]. Thus a competition between metal oxide formation and chemical dissolution continues leading to the formation of nanotubes. This sequence of reactions needs to be controlled to repeatedly fabricate highly-ordered nanotubular morphology. Knowing that the chemistry of the process changes with repeated use of the electrolyte, a better understanding of the manufacturing process is the focus of this work.

Many studies have addressed the growth mechanism and morphologies of $\mathrm{TiO}_{2}$ nano-tubular structures. However, less attention has been paid to the morphological changes upon extensive reuse of the electrolyte, which is critical in a manufacturing scenario.

\section{Materials and Methods}

\subsection{Substrate Preparation}

Foils of Ti6Al4V alpha/beta titanium alloy of ASTM B 265-11 grade 5 (TIMET, USA) and $0.5 \mathrm{~mm}$ thick, were mechanically polished using \#150 grit fine crocus cloth and \#800 grit ultra-fine sanding cloth. After cleaning in deionized (DI) water followed by acetone, the samples were dried in air at room temperature. Coupons $75 \mathrm{~mm} \times 10 \mathrm{~mm}$ $\times 0.5 \mathrm{~mm}$ thick were cut from the foils to etch $1500 \mathrm{~mm}^{2}$ on each sample, including both sides.

\subsection{Fabricating Nanotubular and Nanoporous Structures}

The nano-structures were etched by electrochemical anodization of Ti6Al4V alloy using a DC power source (Protek 3006B), with direct current (DC) output $0-60 \mathrm{~V}, 1.5$ Amp. Electrolyte containing 98\% ethylene glycol, $2 \%$ DI water and 0.66 wt $\%$ of $\mathrm{NH}_{4} \mathrm{~F}$ 
was used for etching. The surfaces were electrochemically anodized at room temperature and $60 \mathrm{~V}$ for 45 minutes with a graphite rod as the cathode and the titanium alloy foil as the anode.

\subsection{Morphological and Compositional Characterization}

Characterization of the anodized surfaces was done using field emission scanning electron microscopy (FE-SEM, Hitachi S-4700). The chemical composition of the TiNT surfaces used energy dispersive spectroscopy (EDS) with standardless quantitative analysis on the FESEM at $10 \mathrm{kV}$. Topographical analysis of the surface texture was conducted using white light interferometric microscopy with nanometer vertical resolution and submicron lateral resolution to measure the volume of the alloy removed upon etching.

\subsection{Measurement of Fluoride-Ion Concentration}

A fluoride ion sensitive electrode ISE (Oakton Instruments, USA) was used for determination of the fluoride concentration in electrolyte samples by direct measurement of fluoride ions after electrode calibration. The electrolyte was mixed by a magnetic stirrer. The $\mathrm{pH}$ and fluoride concentration were measured in the bulk electrolyte prior to anodization of each coupon, and after anodization of each coupon by removing $1 \mathrm{ml}$ of electrolyte and adding $4.5 \mathrm{ml}$ TISAB I buffer solution (Sigma-Aldrich). All measurements were carried out $24^{\circ} \mathrm{C} \pm 4^{\circ} \mathrm{C}$.

Before the measurements, $1 \times$ and $10 \times \mathrm{NaF}$ standard solutions in $50 \mathrm{ml} \mathrm{DI} \mathrm{H}_{2} \mathrm{O}+50$ $\mathrm{ml}$ TISAB I were prepared. These standard solutions were used before starting the experiment for a slope check of the ISE to ensure performance within calibration limits. Additionally, standard solutions using 1, 10, 100, 1000 and 5000 ppm concentrations of $\mathrm{NaF}$ (with TISAB I) and $\mathrm{NH}_{4} \mathrm{~F}$ (with TISAB I and w/o TISAB I) were used to prepare calibration plots. One calibration plot was prepared using NaF + TISAB I + DI water as the fluoride standard solution. The other two calibration plots were prepared using standard solutions of $\mathrm{NH}_{4} \mathrm{~F}+\mathrm{DI}$ water + Ethylene glycol (with TISAB I and w/o TISABI). While preparing the $\mathrm{NH}_{4} \mathrm{~F}$ standard solutions, it was ensured that the molarity of F-ions was between $10^{-1}$ and $10^{-5}$ and the $\mathrm{pH}$ was between 5 and 9 to avoid interference of hydroxide ions on electrode response. TISAB I was added to avoid hydroxide interferences or the formation of hydrogen complexes of fluoride and thus to maintain $\mathrm{pH}$ of standard solution and the $1 \mathrm{ml}$ electrolyte samples.

\subsection{ICP-OES Trace Metal Analysis}

An inductively coupled plasma-optical emission spectrometer (Perkin Elmer, Optima 7000 DV, USA) was used with 1400 Watts RF power to measure $\mathrm{Ti}, \mathrm{Al}$, and V trace metal elements in the electrolyte. Wavelengths of $334.940 \mathrm{~nm}$ for Ti (II), $396.153 \mathrm{~nm}$ for $\mathrm{Al}$ (I) and $292.464 \mathrm{~nm} \mathrm{~V}$ (II) were used. For determination of dissolved metals in the electrolyte after each coupon was anodized, a $10 \mathrm{ml}$ sample form the bulk electrolyte was dried at $250^{\circ} \mathrm{C}$ in Teflon evaporating dishes with subsequent addition of $10 \mathrm{ml}$ 
$2 \%$ nitric solution. All analyses were performed in one replicate of each element and the average values have been reported. The standard measurements ranged from $0.1-20.0$ $\mathrm{mg} / \mathrm{L}$. For the Ti analysis, a 1:10 dilution was made prior to analysis so that the samples fell within the calibration range.

\section{Results and Discussion}

\subsection{Morphological Analysis}

A distinct fluoride rich layer exists between the tube-walls at the triple point of ordered $\mathrm{TiO}_{2}$ nanotubes etched in the electrolyte [10]. The morphological transition from pores to tubes as a result of increased fluoride concentration occurs due to chemical solubility of the triple point cell boundaries where a fluoride rich layer accumulates [11]. The transition from pores to tubes is due to high chemical dissolution occurring in the fluoride rich layer [6]. The fluoride rich boundaries get suppressed in viscous electrolytes which results in formation of nano-pores instead of tubes [9]. Thus the process of morphology transition from pores to tubes is favoured by the fluoride rich layer formed between the nanotube cell boundaries.

The morphological changes in surface aggregate from tubular nano-grass to porous film formation on the top of the surface aggregate was observed with depleting fluoride concentration upon extended use of the electrolyte. Depending on the F-concentration, morphologically different structures were obtained. With fresh electrolyte, distinct nanotubes were fabricated. With well-used electrolyte after 20 coupons, the morphology was much more porous and roughened. The authors hypothesize that upon extended reuse of the electrolyte, the decreased F-ion concentration lowered the ionic migration. Surfaces obtained from electrochemical etching of Ti6Al4V alloy foils in EG-based electrolyte are shown in Figure 1 and Figure 2. Figure 1(a) shows the asanodized surface aggregate which shows a tubular nano-grass obtained in fresh electrolyte. The as-anodized surfaces were always covered with this oxide layer which can be removed with ultrasonication. Figure 1 (b) shows the sonicated surface revealing close packed, well-rounded, open-tubular morphology after removal of the nano-grass. The
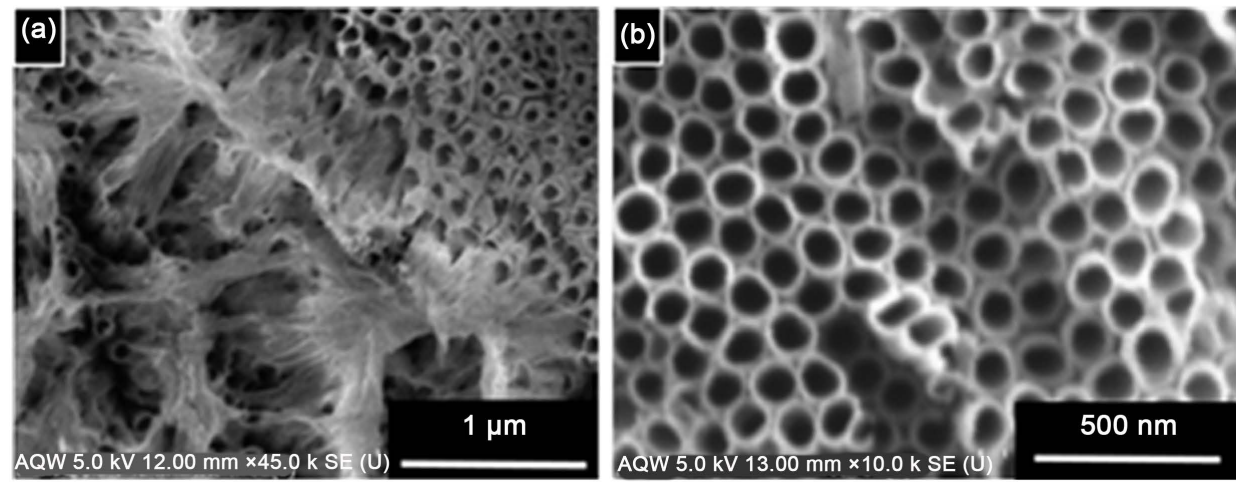

Figure 1. FESEM top view of the nanotextured surface fabricated with fresh electrolyte: (a) As-anodized oxide surface (tubular nano-grass) on top of nanotubes; (b) Ordered network of well-rounded $\mathrm{TiO}_{2}$ nanotubes after ultrasonic agitation. 

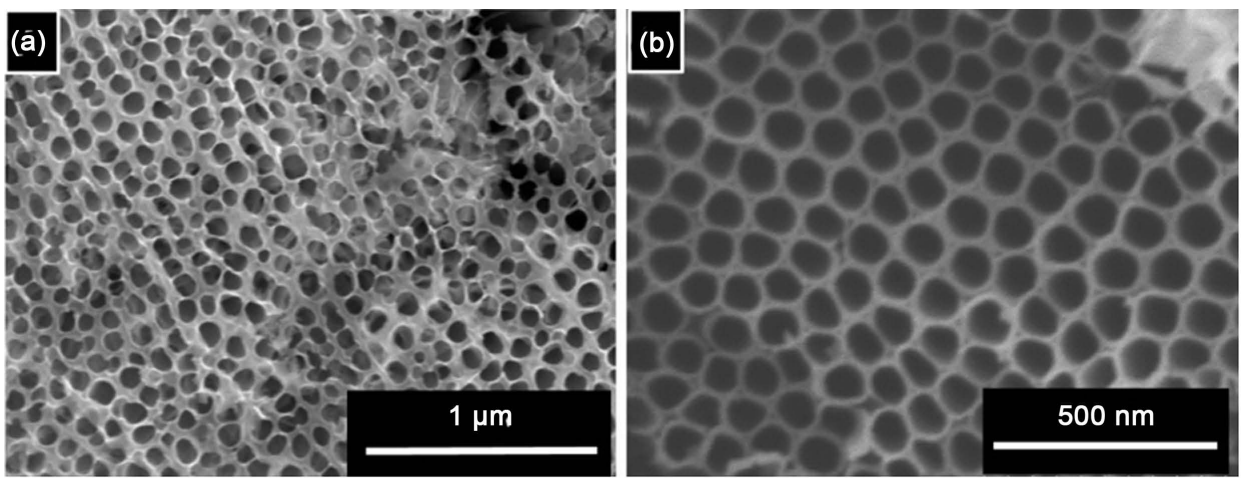

Figure 2. FESEM top view of the nanotextured surface fabricated with reused (aged) electrolyte: (a) As-anodized porous film on the top of surface aggregation; (b) Ordered network of wellrounded $\mathrm{TiO}_{2}$ nanotubes after ultrasonic agitation.

tubes have smooth walls and are well-ordered. In Figure 2, the morphological variation obtained with reused electrolyte in the form of a porous-film on the top of surface aggregation is shown after 22 anodizations on 22 different coupons. Thus, a change in morphology of the surface aggregate occurred, but no significant difference in the tubular morphology underneath was observed with fresh or reused electrolyte. This implies that after anodizing the 22 coupons, there is still enough fluorine in the electrolyte to produce ordered tubular morphology and the minimum concentration of fluoride is not reached which may affect the etched tubular structures underneath.

\subsection{Depletion of Fluoride Concentration vs Cumulative Area Etched}

The fluoride concentration in the electrolyte is an important parameter for controlled electrochemical anodization. A higher fluoride concentration creates higher current densities during anodization [12]. A total of $36,000 \mathrm{~mm}^{2}$ was etched by anodizing 24 coupons each with $1500 \mathrm{~mm}^{2}$ area on each sample. Figure 3(a) summarizes the depleted F-concentration corresponding to the cumulative etched area upon reuse of the electrolyte. The fluoride concentration in the fresh electrolyte was $3033 \mathrm{ppm}$, and decreased to $333 \mathrm{ppm}$ after etching $36,000 \mathrm{~mm}^{2}$. It is evident from these measurements and SEM images that a fluoride concentration control strategy must be advanced. Our results showed a log-linear depletion of F-concentration as a function of area anodized which can be used to effectively adjust the fluorine by periodic addition to the electrolyte. If the F-concentration in the electrolyte reduces below $0.3 \mathrm{wt} \%$ of $\mathrm{NH}_{4} \mathrm{~F}$, it can affect the resulting morphology. Figure 3 (b) summarizes the log-linear relation corresponding to the cumulative etched area upon reuse of the electrolyte. As this technology moves toward integration with current implants, it is required to understand and control the manufacturing process to ensure reproducible results on a large scale and with different sizes of implants based only on the implant surface area.

\subsection{Effect on Current Transients}

TiNT formation is a reflection of current-time transient analysis [6]. The current-time profile during anodization reflects film growth leading to the corresponding morpholo- 
F concentration Vs Cumulative area etched

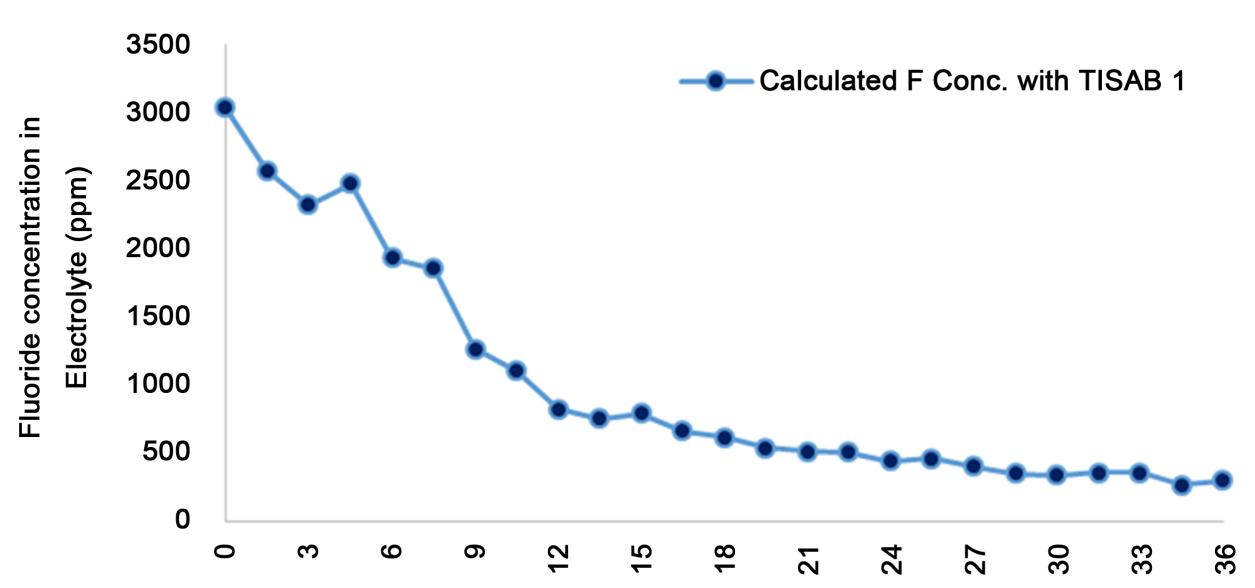

Cumulative area etched $\left(\times 10^{3} \mathrm{~mm}^{2}\right)$

(a)

F ion concentration Vs cumulative area etched (with TISAB I)

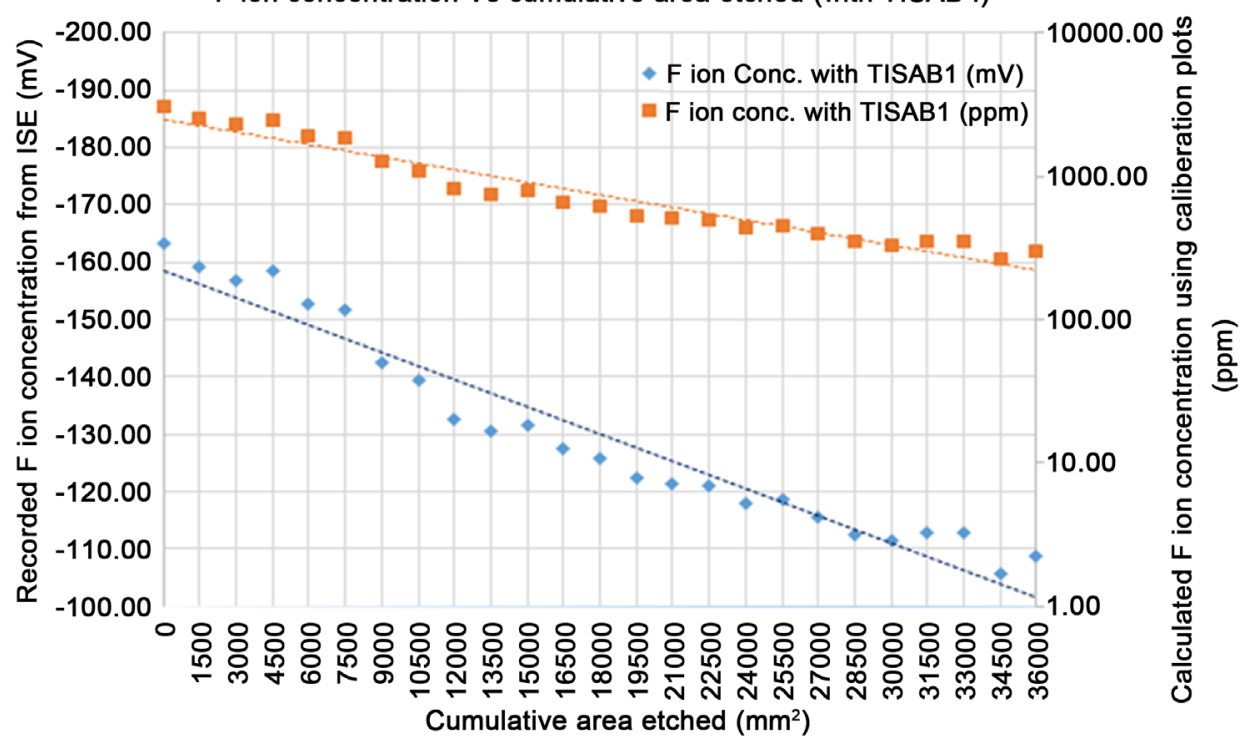

(b)

Figure 3. (a) F-concentration measurement using ion sensitive electrode from electrolyte samples with TISAB I; (b) F-concentration measurement (log-linear relation between the F-concentration and the area anodized).

gies [13]. Variation in current densities affects the etching rate which also causes variation in tube diameters [14]. The higher diffusibility and concentration of ions in aqueous electrolytes gives much higher current densities compared to organic electrolytes [15]. The oxidation of titanium and chemical dissolution creates changes in the electrolyte chemistry. Figure 4 shows three distinct stages of the current-time transient recorded at $60 \mathrm{~V}$ during anodization. Three stages (I, II, III) were observed for samples 2, 10 and 20 etched in the same electrolyte solution. Each sample had an etched area of $1500 \mathrm{~mm}^{2}$. 


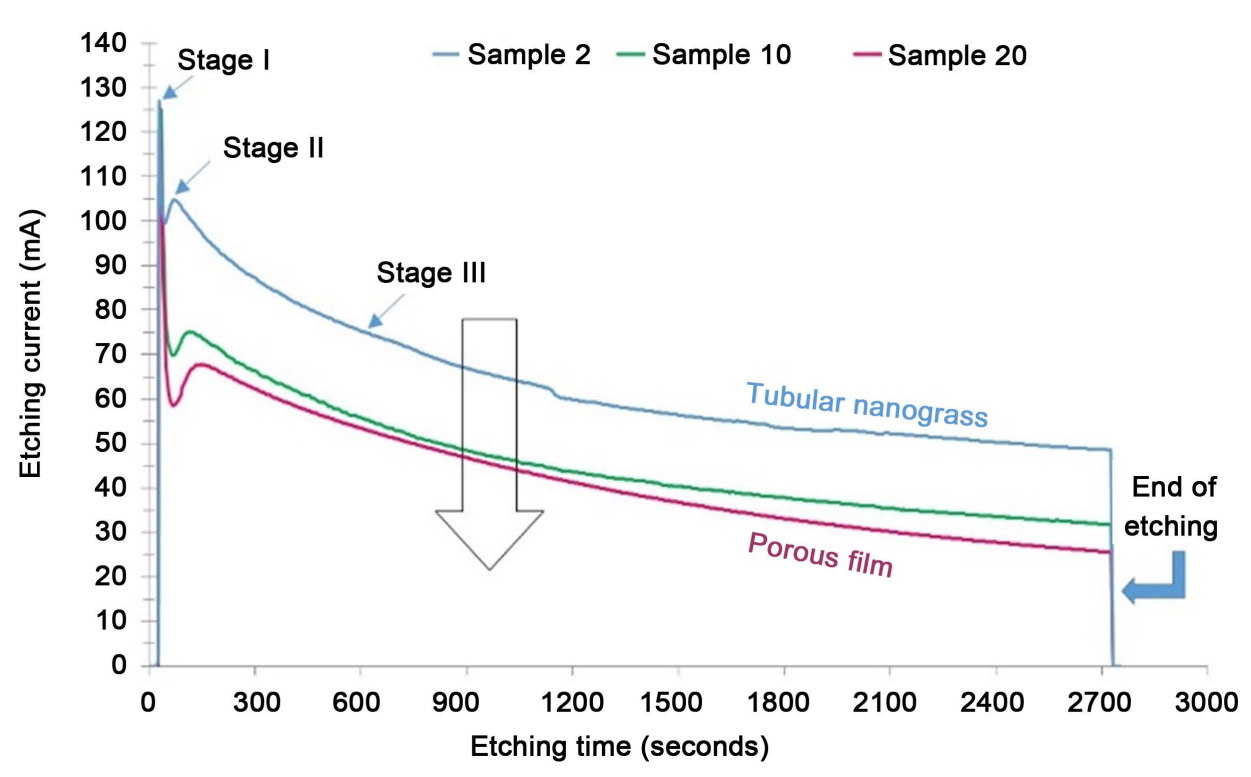

Figure 4. Current-time profile recorded during etching.

At the start of anodization, when the potential is applied, the initial anodic current reached maximum. This initiated the formation of oxide on the metal foil anode. Then, the current quickly dropped showing formation of the oxide layer. During stage II, the resistance of the anodic film decreased and the current density increased demonstrating the pore nucleation due to selective dissolution of oxide by fluoride species. This local breakdown of an initially formed oxide layer caused eventual development of tiny pits and pores in the compact oxide film. This facilitated ion transport causing a slight increase in anodic current [13]. The continued deepening of pores causes the inter-pore sites to become high surface energy regions which attracts more $\mathrm{F}^{-}$ions leading to faster dissolution of oxides there [16]. Finally at stage III, a slowly decreasing current value was attained over the entire anodization time demonstrating steady state formation of nanostructures by field-assisted oxidation and dissolution of metal oxides into the electrolyte. The slight step in sample 2 near 1200 seconds is an artifact of the etching experiment and may have been due to a slight movement of the cathode causing a temporary change in etching rate. This was not seen in any other experiments.

Higher fluoride concentration in the electrolyte creates higher current densities during anodization [12]. Our results show that, the first current peak was observed in approximately the same position for all fluoride concentrations. Just after the first peak, decreased current shown by a distinct second peak demonstrated morphological changes. Thus decreased current densities are the result of depleted fluoride in the electrolyte upon reuse. The formation of fluoride complexes at cell boundaries is an essential condition for higher chemical dissolution of metals to achieve tubular morphology. Hence suppressed dissolution of F-rich layer resulted in morphological variation.

\subsection{Effect on Macroscale Volume Removal}

Figure 5 shows the etched volume of the anodized surfaces using white light interfere- 


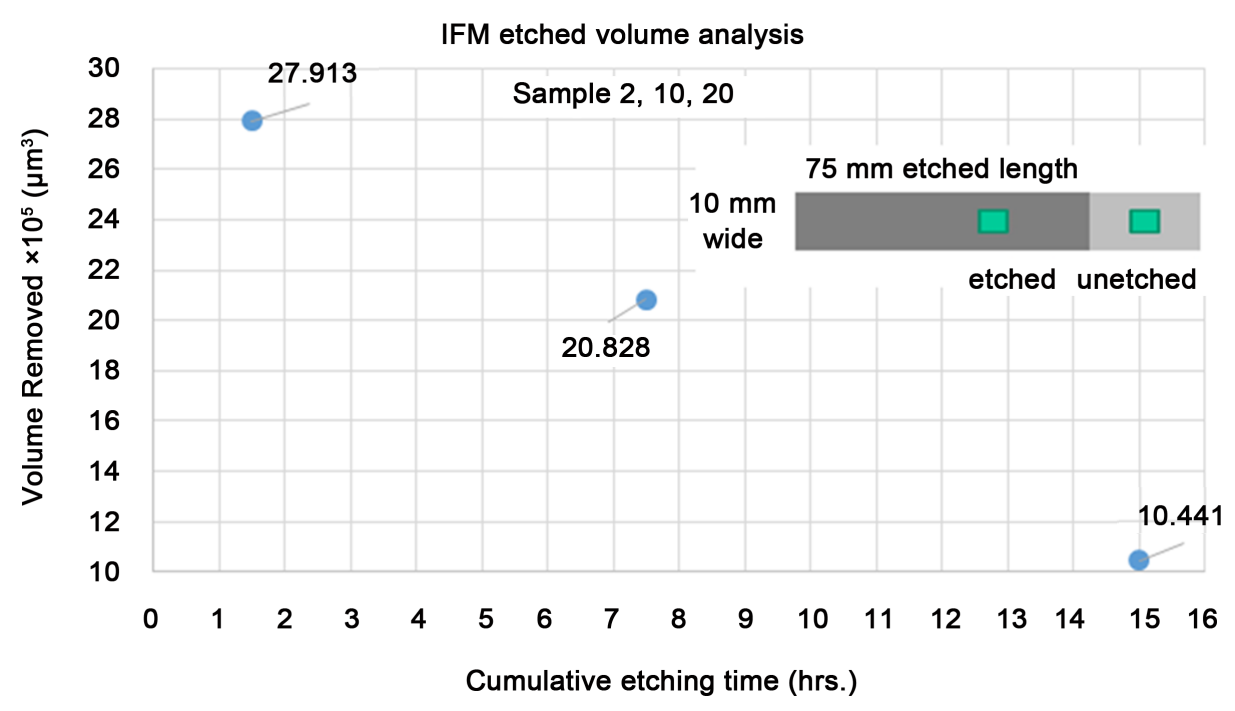

Figure 5. Estimation of volume removed during etching.

ometric microscopy to evaluate volume removed upon etching with respect to cumulative etching time. It was observed that anodization roughens the surfaces. The volume removed during anodization was calculated from the difference between baseline volume of an un-etched area and the final volume of the etched area. The decrease in volume removed during the same anodization duration can be attributed to the depleted fluorine. The variation of the surface topographies due to depleted fluorine is tabulated in Table 1.

\subsection{Electrolyte Contamination Due to Metals Dissolution}

The higher electric field intensity during the initial stage of anodization leads to larger oxide breakdown sites resulting in larger diameter nanotubes. The dissolution rate of oxide formation is affected by the $\mathrm{pH}$ of the electrolyte [17]. More acidic $\mathrm{pH}$ linearly increases the dissolution rate [18]. Figure 6(a) and Figure 6(b) shows ICP-OES measurements of the dissolved titanium, aluminum, and vanadium in the electrolyte. Our results show that reuse of the electrolyte led to a linear increase in metals as would be expected. This analysis provides guidelines for the control of the electrolyte chemistry, for both remaining fluorine and metals contamination, to ensure repeatable results when the electrolyte is reused instead of disposed of reducing environmental impact for large scale manufacturing.

Table 1. 3D topographic parameters of $400 \mu \mathrm{m} \times 400 \mu \mathrm{m}$ scanning area.

\begin{tabular}{ccccc}
\hline Sample \# & $\begin{array}{c}\text { Cumulative } \\
\text { Etching Time } \\
(\text { Hrs. })\end{array}$ & $\begin{array}{c}\text { Final Volume } \\
(\text { Etched Area }) \\
\left(\times 10^{6} \mu \mathrm{m}^{3}\right)\end{array}$ & $\begin{array}{c}\text { Baseline Volume } \\
(\text { Unetched Area }) \\
\left(\times 10^{5} \mu \mathrm{m}^{3}\right)\end{array}$ & $\begin{array}{c}\text { Volume Removed } \\
(\text { Final-Baseline }) \\
\left(\times 10^{5} \mu \mathrm{m}^{3}\right)\end{array}$ \\
\hline 2 & 1.5 & 3.027 & 2.357 & 27.913 \\
10 & 7.5 & 2.328 & 2.452 & 20.828 \\
20 & 15 & 1.313 & 2.689 & 10.441 \\
\hline
\end{tabular}




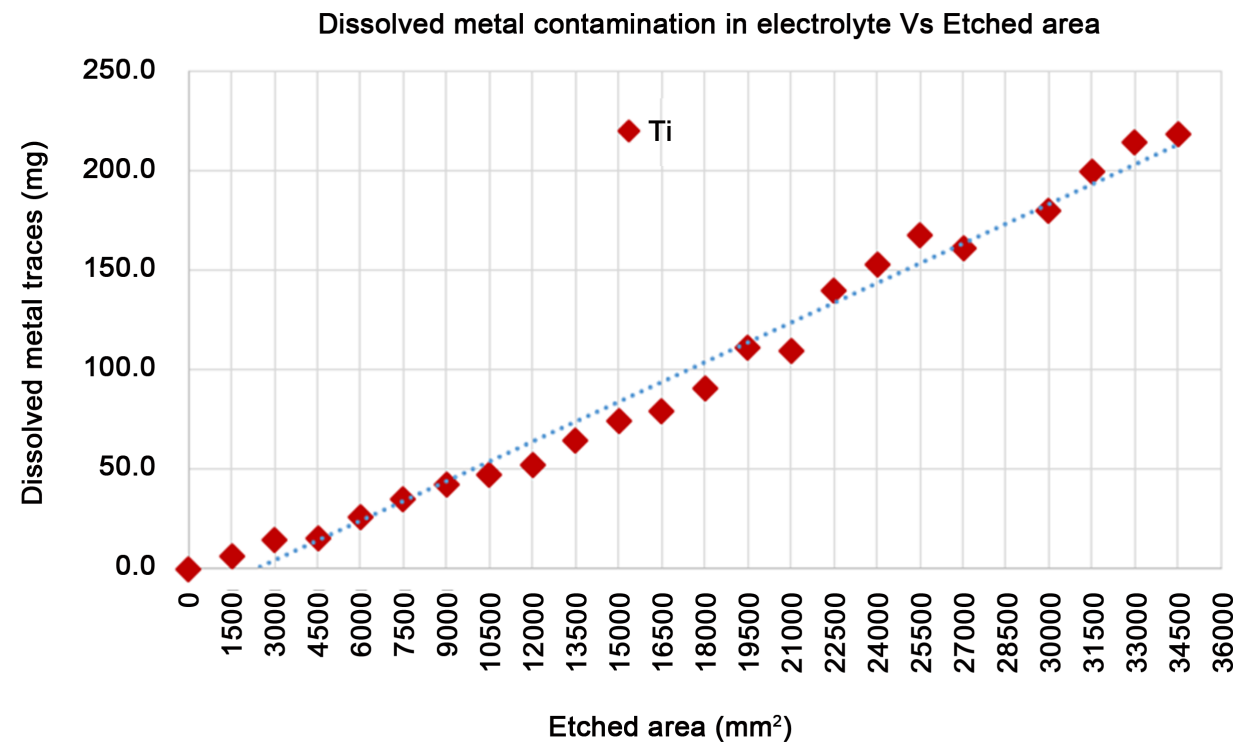

(a)

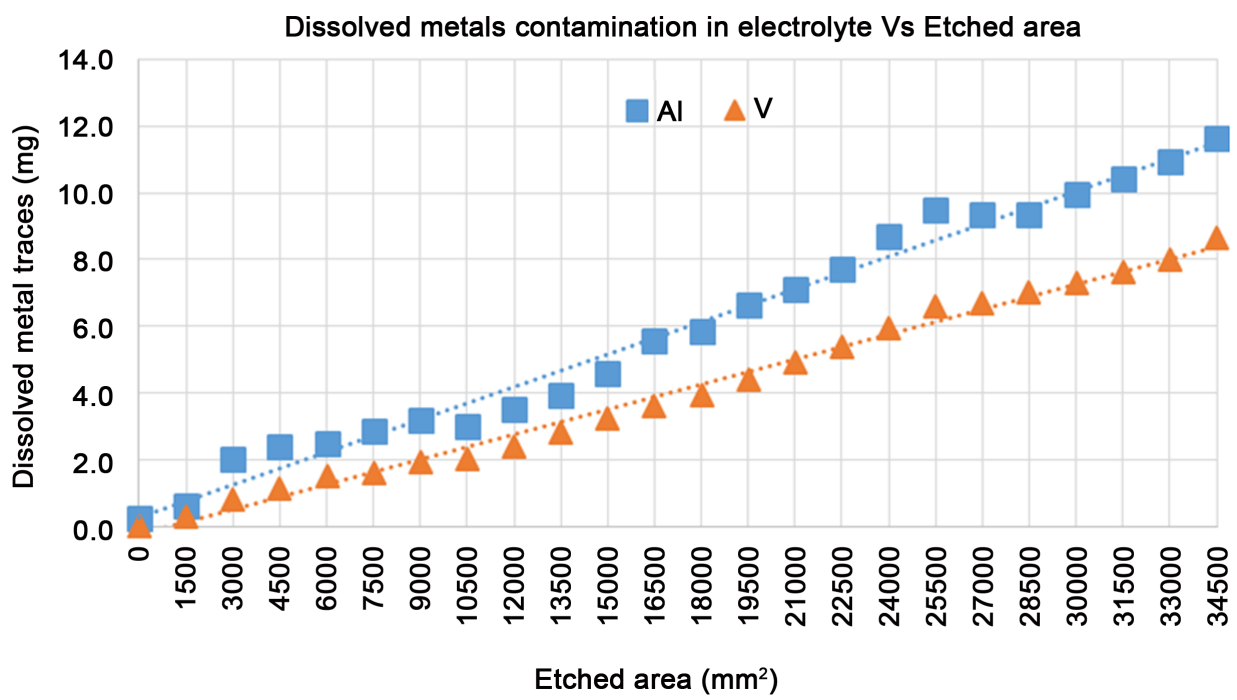

(b)

Figure 6. (a) ICP-OES analysis of titanium contamination in electrolyte; (b) ICP-OES analysis of aluminium and vanadium contamination in electrolyte.

In Figure 4, the current amplitude of sample 2 represents new electrolyte with a higher level of fluorine and fewer non-conductive metal oxide particles distributed in the electrolyte. As cumulative etching progresses, the current decreases in an asymptotic fashion which follows the similar fluorine depletion shown in Figure 3(a). Additionally, the introduction into the electrolyte of the etched oxides of titanium, aluminum, and vanadium shown in Figure 6(a) and Figure 6(b) reduces the electrical conductivity of the electrolyte further reducing etching current. These two combined effects cause the progressive etching current to reduce exponentially to an asymptotic condition similar to Figure 3(a). This is the reason the current traces of samples 10 and 20 are similar 
and nearer in magnitude than sample 2.

The decreasing trend of the etching current over time for a particular sample is primarily due to the formation of the nanotubes that have a relatively high aspect ratio, depth to diameter. Fluorine is the element responsible for etching and as the nanotube is deepened, the local etch rate is diffusion-limited by the ability to introduce fluorine at the inside bottom of the nanotube. As the nanotube grows deeper, the fluorine concentration at the bottom reduces due to this diffusion-limited effect and the overall etch rate, and therefore etching current reduces. Thus besides F depletion, the other subsequent effects such as decrease in etching current occurred because of eventually dissolved metals contamination are also important.

\subsection{EDS Analysis}

Chemical compositional analysis of the anodized surfaces by EDS was also undertaken and typical results are shown in Table 2. The structures were characterized to compare the effect of the fresh and reused electrolyte. The greatly increased oxygen content represents the formation of the stable oxide during anodization. The structures obtained using fresh electrolyte shows $35 \mathrm{wt} \%$ oxygen and $12 \mathrm{wt} \%$ residual fluorine, whereas the structure obtained using aged electrolyte shows $27 \mathrm{wt} \%$ oxygen and $9 \mathrm{wt} \%$ residual fluorine. The lower residual fluorine with the reused electrolyte reflects the depleted fluorine in the electrolyte. During anodization, the growth of nanotubes leads to the formation of hexafluorotitanate complex $\mathrm{TiF}_{6}^{2-}$ by fluorine diffusion from electrolyte to titanium [4]. The presence of fluorine in the anodized surfaces is indicative of the diffused $\mathrm{TiF}_{6}^{2-}$ during etching rather than free fluoride ions. The decreased fluorine $w t \%$ observed in nanotextured surfaces can be attributed to fewer $\mathrm{TiF}_{6}^{2-}$ complexes formed.

\section{Conclusions}

The experimental results of reusing the electrolyte for many samples, rather than disposing the electrolyte after each use, lead to several important conclusions from a manufacturing perspective. First, the amount of fluorine removed from the electrolyte is accounted for by its presence in the anodized surface. This fluorine may be of benefit as the hydroxyapatite of bone contains fluorine. However, this effect is still to be determined from a biological perspective. From a manufacturing control perspective, the reduction of fluorine in the electrolyte available for repeatable anodization of nano-

Table 2. Relative chemical composition of control and as-anodized surfaces.

\begin{tabular}{cccccc}
\hline \multirow{2}{*}{ TiNTs and TiNPs on alloy } & \multicolumn{5}{c}{ wt \% of elements } \\
\cline { 2 - 6 } & $\mathrm{Ti}$ & $\mathrm{Al}$ & $\mathrm{V}$ & $\mathrm{F}$ & $\mathrm{O}$ \\
\hline Control & 88.68 & 7.27 & 3.90 & 0 & 0.15 \\
Tubular nano-grass (sample\#1) & 47.51 & 3.64 & 2.57 & 11.99 & 34.29 \\
Porous nano-film (Sample \#23) & 56.30 & 3.51 & 2.76 & 9.46 & 27.98 \\
\hline
\end{tabular}


structures reduces in a log-linear fashion, in this case from an initial value of approximately $3000 \mathrm{ppm}$ to approximately $300 \mathrm{ppm}$ after $36,000 \mathrm{~mm}^{2}$ was etched. Such a behaviour leads to a relatively easy prediction of the remaining fluorine concentration as a function of implant area etched, knowing the initial concentration. This strategy would replenish fluorine periodically depending on the total or incremental area of implants anodized. This control is important as we have shown that the volume of the implant removed varies as the electrolyte is reused, leading to a variable morphology progressing from distinct nanotubes to a more simple porous surface. By knowing a priori the area of each duplicate or different implant in a manufacturing process, the fluorine content in the electrolyte could be controlled.

The metal removed from the surface during anodization is accounted for in the electrolyte. Again, the presence of each alloying element in the electrolyte increases in a linear fashion. EDS has been conducted on the cathode used in the process and there are no metals present so the electrolyte represents all metal removed. With this wellbehaved increase in metals in the electrolyte, removal of those metal particles by batch centrifugation or continuous filtration, will provide for easy process control.

\section{Acknowledgements}

This work performed under the M-TRAC program was supported by Grant Case-48161 of the 21st Century Jobs Trust Fund received through the Michigan Strategic Fund from the State of Michigan. The M-TRAC program is funded by the Michigan Strategic Fund with program oversight by the Michigan Economic Development Corporation.

\section{References}

[1] Macak, J.M., Tsuchiya, H., Taveira, L., Ghicov, A. and Schmuki, P. (2005) Self-Organized Nanotubular Oxide Layers on Ti-6Al-7Nb and Ti-6Al-4V Formed by Anodization in $\mathrm{NH}_{4} \mathrm{~F}$ Solutions. Journal of Biomedical Materials Research, 75A, 928-933. http://dx.doi.org/10.1002/jbm.a.30501

[2] Bojian, L., Shunsuke, F., Masashi, N., Jiro, T., Hyun-Min, K., Masaki, U., Tadashi, K. and Takashi, N. (2003) Histological and Mechanical Investigation of the Bone-Bonding Ability of Anodically Oxidized Titanium in Rabbits. Biomaterials, 24, 4959-4966. http://dx.doi.org/10.1016/S0142-9612(03)00421-6

[3] Baoe, L., et al. (2014) Improvement of Biological Properties of Titanium by Anodic Oxidationand Ultraviolet Irradiation. Applied Surface Science, 307, 202-208. http://dx.doi.org/10.1016/j.apsusc.2014.04.015

[4] Macak, J.M., Tsuchiya, H., Ghicov, A., Yasuda, K., Hahn, R., Bauer, S. and Schmuki, P. (2007) $\mathrm{TiO}_{2}$ Nanotubes: Selforganized Electrochemical Formation, Properties and Applications. Current Opinion in Solid State and Material Science, 11, 3-18. http://dx.doi.org/10.1016/j.cossms.2007.08.004

[5] Yin, H., Liu, H. and Shen, W.Z. (2010) The Large Diameter and Fast Growth of SelfOrganized $\mathrm{TiO}_{2}$ Nanotube Arrays Achieved via Electrochemical Anodization. Nanotechnology, 21, 035601-07. http://dx.doi.org/10.1088/0957-4484/21/3/035601

[6] Regonini, D., Bowen, C.R., Jaroenworaluck, A. and Stevens, R. (2013) A Review of Growth Mechanism, Structure and Crystallinity of Anodized $\mathrm{TiO}_{2}$ Nanotubes. Materials Science and Engineering: R: Reports, 74, 377-406. http://dx.doi.org/10.1016/j.mser.2013.10.001 
[7] Alain, R., Michele, B., Jorge, L.R., Roberto, Z.N. and Messias, B.S. (2014) Formation of $\mathrm{TiO}_{2}$ Nanotube Layer by Anodization of Titanium in Ethylene Glycol- $\mathrm{H}_{2} \mathrm{O}$ Electrolyte. Journal of Surface Engineered Materials and Advanced Technology, 4, 123-130. http://dx.doi.org/10.4236/jsemat.2014.43016

[8] Yardnapar, P., Puangrat, K., Sirinrath, S. and Preecha, T. (2014) Hydroxyapatite Electrodeposition on Anodized Titanium Nanotubes for Orthopedic Applications. Applied Surface Science, 311, 54-61. http://dx.doi.org/10.1016/j.apsusc.2014.04.207

[9] Ghafar, A., Chong, C., Seung, H.Y., Jong, M.K. and Sung, O.C. (2011) Fabrication of Complete Titania Nanoporous Structures via Electrochemical Anodization of Ti. Nanoscale Research Letters, 6, 332-341. http://dx.doi.org/10.1186/1556-276X-6-332

[10] Steffen, B., Sergiu, P.A., Felix, S., Helga, H., Schmuki, P., Hammond, J.S., Paul, D.F. and Reichlmaier, S. (2011) The Origin for Tubular Growth of $\mathrm{TiO}_{2}$ Nanotubes: A Fluoride Rich Layer between Tube-Walls. Surface Science, 605, 57-60.

http://dx.doi.org/10.1016/j.susc.2011.06.019

[11] Roy, P., Berger, S. and Schmuki, P. (2011) $\mathrm{TiO}_{2}$ Nanotubes: Synthesis and Applications. Angewandte Chemie International Edition, 50, 2904-2939.

http://dx.doi.org/10.1002/anie.201001374

[12] Macak, J.M., Hildebrand, H., Marten, J.U. and Schmuki, P. (2008) Mechanistic Aspects and Growth of Large Diameter Self-Organized $\mathrm{TiO}_{2}$ Nanotubes. Journal of Electroanalytical Chemistry, 621, 254-266. http://dx.doi.org/10.1016/j.jelechem.2008.01.005

[13] Liu, H., Tao, L. and Shen, W.Z. (2011) Controllable Current Oscillation and Pore Morphology Evolution in the Anodic Growth of $\mathrm{TiO}_{2}$ Nanotubes. Nanotechnology, 22, 155603-14. http://dx.doi.org/10.1088/0957-4484/22/15/155603

[14] Tsuchiya, H., Macak, J.M. and Ghicov, A. (2007) Characterization of Electronic Properties of $\mathrm{TiO}_{2}$ Nanotube Films. Corrosion Science, 49, 203-210. http://dx.doi.org/10.1016/j.corsci.2006.05.009

[15] Hiroaki, T., Macak, J.M., Taveira, L., Balaur, E., Ghicov, A., Sirotna, K. and Schmuki, P. (2005) Self-Organized $\mathrm{TiO}_{2}$ Nanotubes Prepared in Ammonium Fluoride Containing Acetic acid Electrolytes. Electrochemistry Communications, 7, 576-580. http://dx.doi.org/10.1016/j.elecom.2005.04.008

[16] Cao, C.B., Li, J.L., Wang, X., Song, X.P. and Sun, Z.Q. (2011) Current Characterization and Growth Mechanism of Anodic Titania Nanotube Arrays. Journal of Materials Research, 26, 437-442. http://dx.doi.org/10.1557/jmr.2010.33

[17] Indira, K., Kamachi, M., Nishimura, T. and Rajendran, N. (2015) A Review on $\mathrm{TiO}_{2}$ Nanotubes: Influence of Anodization Parameters, Formation Mechanism, Properties, Corrosion Behaviour and Biomedical Applications. Journal of Bio- and Tribo-Corrosion, 1, 28. http://dx.doi.org/10.1007/s40735-015-0024-x

[18] Macak, J.M., Tsuchiya, H. and Schmuki, P. (2005) High-Aspect-Ratio $\mathrm{TiO}_{2}$ Nanotubes by Anodization of Titanium. Angewandte Chemie International Edition, 44, 2100-2102. http://dx.doi.org/10.1002/anie.200462459 
Submit or recommend next manuscript to SCIRP and we will provide best service for you:

Accepting pre-submission inquiries through Email, Facebook, LinkedIn, Twitter, etc. A wide selection of journals (inclusive of 9 subjects, more than 200 journals)

Providing 24-hour high-quality service

User-friendly online submission system

Fair and swift peer-review system

Efficient typesetting and proofreading procedure

Display of the result of downloads and visits, as well as the number of cited articles

Maximum dissemination of your research work

Submit your manuscript at: http://papersubmission.scirp.org/

Orcontact jsemat@scirp.org 